\title{
Investigando as Dificuldades e Perspectivas sobre um Curso de Engenharia de Software de Dois Ciclos: Um Survey com a Visão Discente
}

\author{
Reudismam Rolim de Sousa \\ Universidade Federal Rural do Semi-Árido \\ Pau dos Ferros, RN, Brazil \\ reudismam.sousa@ufersa.edu.br \\ Samara Martins Nascimento \\ Universidade Federal Rural do Semi-Árido \\ Pau dos Ferros, RN, Brazil \\ samara.nascimento@ufersa.edu.br
}

\author{
Jarbele Cássia da Silva Coutinho \\ Universidade Federal Rural do Semi-Árido \\ Pau dos Ferros, RN, Brazil \\ jarbele.coutinho@ufersa.edu.br \\ Felipe Torres Leite \\ Universidade Federal Rural do Semi-Árido \\ Pau dos Ferros, RN, Brazil \\ felipe.leite@ufersa.edu.br
}

\begin{abstract}
RESUMO
Os cursos de graduação de Engenharia de Software (ES) buscam realizar a formação de novos profissionais, visando estabelecer conhecimentos técnicos e científicos para auxiliar no processo de construção e desenvolvimento de projetos tecnológicos. No entanto, dificuldades são percebidas ao estruturar os cursos de graduação para atender as diferentes demandas da área, voltadas para o mercado de trabalho, ensino, pesquisa e extensão. Assim, este estudo busca identificar os desafios, as percepções e as limitações dos discentes que cursam uma graduação em ES, no formato de dois ciclos. Para isto, foi aplicado um Survey para coleta de dados e, em seguida, foi realizada uma análise quali-quantitativa das informações coletadas. Os resultados apontaram desafios no $1^{\circ}$ ciclo relacionados à (i) pouca prática em conteúdos ministrados, (ii) desmotivação com o curso devido à dificuldade em programar e (iii) quantidade de conteúdos teóricos ministrados por docentes. Já no $2^{\circ}$ ciclo, relacionados à (i) falta de recursos bibliográficos atuais, (ii) indisponibilidade de algumas ferramentas gratuitas e (iii) conteúdos ministrados ainda de forma muito teórica. Desta forma, os resultados deste estudo contribuirão para uma análise de melhores intervenções nas atividades desempenhadas no referido curso.
\end{abstract}

\section{PALAVRAS-CHAVE}

Engenharia de Software, Educação, Survey.

\section{INTRODUÇÃO}

Tradicionalmente, os profissionais de software são formados em cursos de graduação, como Ciência da Computação (CC), Engenharia de Software (ES) e Sistemas de Informação (SI) [1, 2]. No caso de ES, seu primeiro curso de graduação no Brasil surgiu no ano de 2008, na Universidade de Brasília (UnB) [3]. Notadamente, muitos são os desafios que têm acompanhado estes cursos para manter

Fica permitido ao(s) autor(es) ou a terceiros a reprodução ou distribuição, em parte ou no todo, do material extraído dessa obra, de forma verbatim, adaptada ou remixada, bem como a criação ou produção a partir do conteúdo dessa obra, para fins não comerciais, desde que sejam atribuídos os devidos créditos à criação original, sob os termos da licença CC BY-NC 4.0.

EduComp'21, Abril 27-30, 2021, Jataí, Goiás, Brasil (On-line)

(c) 2021 Copyright mantido pelo(s) autor(es). Direitos de publicação licenciados à Sociedade Brasileira de Computação (SBC) o processo de ensino-aprendizagem adequado para atuação dos discentes como futuros profissionais no mercado de trabalho [4].

É importante destacar que o papel do profissional de software não se limita a conhecimentos técnicos, exigindo aptidões e habilidades tais como empreendedorismo, gestão de projetos, conhecimento de mercado, aplicação de tecnologias específicas, dentre outros. Para alinhar o processo de ensino com as demandas atuais do mercado de trabalho, espera-se que o currículo na área de ES se estenda para além do formato de aula expositiva, considerando variações de técnicas de ensino e aprendizagem $[5,6]$ e envolvendo o discente em experiências reais de processos de desenvolvimento de software.

Com o constante avanço das tecnologias e as requisições cada vez mais específicas da indústria de software emerge a necessidade do alinhamento dessas demandas com os conteúdos dos cursos da área de Computação, a exemplo dos cursos de ES [4]. Logo, alguns estudos foram realizados com o objetivo de identificar o panorama do ensino de ES, baseados no uso de técnicas, ferramentas e experiências e do ponto de vista de docentes da área [4, 7-10].

Com o objetivo de investigar as reais dificuldades e perspectivas de discentes de um curso de ES. Este trabalho empregou um Survey com discentes matriculados em um curso de graduação em ES, ofertado em um formato de dois ciclos, da Universidade Federal Rural do Semi-Árido, Centro Multidisciplinar de Pau dos Ferros - RN (UFERSA-CMPF). Um curso de $1^{\circ}$ ciclo fornece ao discente o grau de bacharel em uma formação interdisciplinar, permitindo que ele realize uma ou várias graduações de $2^{\circ}$ ciclo ou optar pela graduação de $1^{\circ}$ ciclo apenas.

Os resultados revelam informações relacionadas (i) às características do perfil discente; (ii) ao grau de dificuldade nas disciplinas cursadas; (iii) aos recursos materiais utilizados; (iv) às dificuldades relacionadas ao aprendizado; (v) às percepções acerca da matriz curricular, dos estágios supervisionados e trabalhos de conclusão de curso; e (vi) às perspectivas dos discentes em relação ao futuro profissional. Espera-se que os resultados encontrados proporcionem uma reflexão sobre a atuação do curso de ES em formato de dois ciclos, bem como sobre uma formação acadêmica-profissional alinhada à real necessidade e demanda da indústria de software.

O restante deste artigo está estruturado da seguinte forma: na Seção 2 é apresentada uma breve contextualização da Engenharia de Software como curso de graduação. Na Seção 3 são expostos alguns 
dos principais trabalhos relacionados ao presente estudo. Na Seção 4 é abordada a metodologia de pesquisa deste estudo, elencando o planejamento, execução e procedimentos de análise. Na Seção 5 são apresentados os resultados, em resposta às questões de pesquisa definidas. Na Seção 6 os resultados são discutidos. Finalmente, na Seção 7 são abordadas as conclusões desta pesquisa.

\section{ENGENHARIA DE SOFTWARE: UMA GRADUAÇÃO EM DOIS CICLOS}

Desde o ano de 2008, surgiram diversos cursos de Engenharia de Software no Brasil [11], sendo o primeiro deles, na UnB; seguido pelas Universidades Federais de Goiás (UFG) e do Ceará (UFC), já no ano de 2009. Após dez anos (em 2018), o total de cursos de graduação em ES já chegava a um total de 51 cursos [11]. Dentre eles, está o bacharelado em ES da UFERSA-CMPF.

O bacharelado em ES da UFERSA-CMPF é ofertado no formato de ensino presencial, como um curso de dois ciclos, desde o ano de 2015 [12]. O seu $1^{\circ}$ ciclo tem a duração média de 3 (três) anos e possui 80 vagas autorizadas por Período Letivo (PL), enquanto que o $2^{\circ}$ ciclo tem a duração média de 2 (dois) anos e possui 30 vagas disponíveis por PL.

$\mathrm{O} 1^{\circ}$ ciclo se enquadra na modalidade de um Bacharelado Interdisciplinar (BI), correspondente a um programa de formação em nível de graduação de natureza geral, que conduz à diplomação, organizado por grandes áreas do conhecimento [13]. Os BIs proporcionam uma formação com foco na interdisciplinaridade e no diálogo entre áreas de conhecimento e entre componentes curriculares, estruturando as trajetórias formativas na perspectiva de uma alta flexibilização curricular [13].

$\mathrm{O} 1^{\circ}$ ciclo é composto por três eixos: i) básico, correspondente às disciplinas básicas comuns à formação em Tecnologia da Informação (TI); ii) profissionalizante, composto por disciplinas comuns a qualquer área de TI; e iii) específico, com disciplinas direcionadas à formação específica do $2^{\circ}$ ciclo. As disciplinas obrigatórias são aquelas que pertencem aos eixos básico e profissionalizante.

Uma vez concluída a graduação do $1^{\circ}$ ciclo, o discente poderá realizar sucessivas graduações de $2^{\circ}$ ciclo, respeitando os critérios de seleção e conclusão do(s) curso(s) escolhido(s) ou não prosseguir para uma segunda graduação.

Na UFERSA-CMPF, o discente graduado no $1^{\circ}$ ciclo pode optar por seguir a sua formação acadêmica em um dos cursos de $2^{\circ}$ ciclo ofertados: graduação em Engenharia de Computação (EC) ou em Engenharia de Software. No caso da graduação em ES, o Projeto Pedagógico do Curso (PPC) [12] estabelece o curso de Bacharelado Interdisciplinar em Tecnologia da Informação (BTI) como correspondente ao seu $1^{\circ}$ ciclo.

Assim sendo, a formação completa na graduação de $1^{\circ}$ e $2^{\circ}$ ciclo em ES propicia ao discente uma formação robusta para a atuação em projetos e em desenvolvimento de software e de sistemas computacionais de qualidade, de maneira inovadora e crítica [12], em conformidade com as referências nacionais e internacionais da área de Engenharia de Software [14-16].

A Tabela 1 apresenta uma síntese de dados quantitativos sobre número de matrículas, desistências e conclusões dos discentes em cada PL, desde o início do curso na UFERSA-CMPF.
Tabela 1: Quantitativo de discentes de ES na UFERSA-CMPF

\begin{tabular}{c|c|c|c|c|c} 
& PL & NM & ND & NC & NA \\
\hline \multirow{7}{*}{$1^{\circ}$ Ciclo } & 2015.2 & 80 & 55 & 10 & 14 \\
& 2016.1 & 80 & 53 & 4 & 20 \\
& 2016.2 & 80 & 53 & 4 & 23 \\
& 2017.1 & 80 & 43 & 1 & 35 \\
& 2017.2 & 82 & 47 & - & 35 \\
& 2018.1 & 80 & 33 & - & 45 \\
& 2018.2 & 80 & 27 & - & 48 \\
& 2019.1 & 80 & 14 & - & 63 \\
& 2019.2 & 83 & 8 & - & 74 \\
& $2020.1^{*}$ & 80 & 3 & - & 77 \\
& Subtotal 1 & 805 & 336 & 19 & 434 \\
\hline \multirow{5}{*}{$2^{\circ}$ Ciclo } & PL & NM & ND & NC & NA \\
\hline & 2018.2 & 1 & - & - & 1 \\
& 2019.1 & 5 & - & 1 & 4 \\
& 2019.2 & 2 & - & - & 1 \\
& $2020.1^{*}$ & 4 & - & - & 4 \\
& Subtotal 2 & 12 & 0 & 1 & 10 \\
\hline
\end{tabular}

Legenda: (NM: $\mathrm{N}^{\circ}$ de Matrículas; ND: $\mathrm{N}^{\circ}$ de Desistências; NC: $\mathrm{N}^{\circ}$ de Concluintes; NA: $\mathrm{N}^{\circ}$ de Ativos; ${ }^{*}$ : PL em andamento)

O Número de Desistências (ND) denota a quantidade de cancelamentos de matrículas realizadas pelos discentes. Já o Número de Ativos (NA) representa a quantidade de alunos que ingressaram em um determinado PL e que ainda possuem matrícula ativa no curso. Destaca-se que o NA não é necessariamente representado pela subtração do Número de Matrícula (NM) pelo ND e Número de Concluintes (NC) do PL. Isto porque o curso permite que discentes possam trancar a matrícula temporariamente, para depois regressarem. Neste caso, o respectivo discente torna-se inativo temporariamente - não o contabilizando em NA - e poderá regressar ao curso, conforme regras da instituição. Logo, o ND representa somente a quantidade de alunos que cancelaram sua matrícula na instituição, implicando na desistência do curso.

Atualmente, existem 434 discentes com matrícula ativa no curso de $1^{\circ}$ ciclo e 10 discentes com matrícula ativa no curso de $2^{\circ}$ ciclo. A disparidade entre os NAs do curso, em cada ciclo, é justificada porque $41,7 \%$ dos discentes desistiram do curso no $1^{\circ}$ ciclo - considerando a proporção ND (336) por NM (805).

Considerando a taxa de desistência do PL 2015.2 a 2017.2, percebese um ND equivalente a $62,4 \%$, em relação ao NM. Ao considerar os PLs 2018.1 e 2019.1, esta taxa reduz para 30,8\%, em relação ao NM. É válido salientar que o maior índice de desistência está presente nos dois períodos iniciais do $1^{\circ}$ ciclo e, para esta análise, foram considerados apenas os PLs já concluídos.

A primeira turma do $1^{\circ}$ ciclo, deste curso de ES, foi iniciada no PL de 2015.2 e este ciclo obteve seu primeiro discente concluinte no PL de 2018.1. Até o momento deste estudo foram graduados 19 discentes. Já a primeira turma do $2^{\circ}$ ciclo deste curso de ES foi iniciada no PL 2018.2 e, deste então, apenas 1 (uma) discente foi graduada, no PL 2020.1.

Os dados apresentados na Tabela 1 apontam para a necessidade de compreender as causas que levam os discentes a evadirem do curso ou não prosseguirem a graduação ofertada no $2^{\circ}$ ciclo do curso 
de ES. Investigar tais aspectos, do ponto de vista dos discentes e compreender as dificuldades que enfrentam durante esta graduação, em um formato de dois ciclos, permitirá o planejamento e desenvolvimento de ações mais efetivas para elevar as quantidades de integralizações no $1^{\circ}$ ciclo e de ingressos no $2^{\circ}$ ciclo.

\section{TRABALHOS RELACIONADOS}

Por meio de um levantamento bibliográfico foram encontrados alguns estudos recentes que investigaram as dificuldades enfrentadas em cursos de graduação de ES no Brasil e propuseram estratégias para apoiar o desenvolvimento destes cursos [8, 10, 17-20].

Leite et al. (2020) realizaram um relato de experiência dos desafios de um curso de ES em dois ciclos na UFERSA-CMPF. Empregou-se um Survey com os docentes para identificar as dificuldades associadas ao curso e elencar os tópicos emergentes. Foram percebidas dificuldades relacionadas à pedagogia, aos recursos materiais, ao aluno e ao conteúdo lecionado. Diferentemente, este trabalho investiga os aspectos referentes à visão dos discentes, de modo a complementar os resultados expostos em Leite et al. (2020).

Ferreira et al. (2018) investigaram as dificuldades e tópicos emergentes no ensino de ES por meio de um Survey com professores de disciplinas de ES no Brasil. Além das dificuldades e tópicos emergentes, eles propõem a categorização das dificuldades identificadas em quatro grupos: pedagogia, recursos materiais, alunos e conteúdo lecionado. De outra forma, este trabalho se aplica a uma graduação em ES em dois ciclos, mas a categorização de Ferreira et al. (2018) contribuiu para a elaboração do Survey aplicado nesta pesquisa.

Andrade et al. (2017) descrevem o processo de ensinoaprendizagem em 10 anos da disciplina de ES do Departamento de Computação da UFC. Para analisá-lo, foram realizadas três avaliações: (i) análise das notas dos alunos; (ii) Survey para identificar a percepção dos alunos; (iii) Survey com os monitores para coletar o feedback deles. Os resultados indicaram melhores notas no decorrer dos anos e reforçam a importância de apresentar os profissionais de ES para motivar o estudo da área, incluir aulas dinâmicas na metodologia de ensino e considerar o apoio de monitores na disciplina. Por outro lado, este trabalho busca investigar características referentes a uma graduação em ES e não a disciplina de ES.

Em Portela et al. (2015) é apresentado um Survey sobre a adoção e aprendizagem de tópicos de ES recomendados pelos currículos de referência da ACM/IEEE e SBC. Realizou-se o estudo com 47 alunos e 23 professores de graduações em Computação de 20 instituições de ensino públicas e privadas do Brasil. Os resultados indicam 6 unidades de conhecimento da ES consideradas mais relevantes nas ementas da disciplina de ES: Engenharia de Requisitos, Processos de Software, Gerenciamento de Projetos, Projeto de Software, Verificação e Validação e Ferramentas e Ambientes; enquanto outras 4 unidades foram consideradas menos relevantes: Confiabilidade de Software, Métodos Formais, Construção de Software e Evolução de Software. Identificou-se também que os alunos consideram atividades práticas mais efetivas para o aprendizado. De outra forma, este trabalho aborda um curso de ES, ao invés da disciplina de ES.

Ramos et al. (2018) apresentam um relato de experiência na adoção de metodologia ativa de aprendizagem, o Team Based Learning (TBL), em uma graduação em ES da UnB. Acompanhou-se a adoção da TBL em assuntos como Requisitos, Medição e Análise e Verificação e Validação de Software, constatando um maior envolvimento dos alunos. Os alunos e professores foram favoráveis ao uso da TBL e fornecem subsídios para reflexões sobre melhorias. Percebeu-se também a ausência de suporte de ferramentas para algumas características específicas da TBL. Diferentemente, o trabalho corrente aborda uma graduação ao invés de uma disciplina de ES e diversos aspectos deste, não apenas uma metodologia de ensino específica.

Lopes et al. (2017) discutem um relato de experiência do uso da metodologia de Aprendizagem Baseada em Problemas (ABP) desenvolvida em uma disciplina da graduação em ES da Universidade Federal do Pampa (UNIPAMPA). Foi realizado um Survey com discentes para avaliar a escolha de problemas da comunidade. Os resultados mostraram que os discentes se estimulam para resolver um problema real e isto permitiu a vivência de situações semelhantes àquelas do mercado de trabalho. Além das características referentes à metodologia, o trabalho proposto investiga vários aspectos de um curso de ES em dois ciclos.

Dutra et al. (2017) apresentaram uma análise sobre a percepção dos alunos da Agência Experimental de Engenharia de Software (AGES) da Pontifícia Universidade Católica do Rio Grande do Sul (PUCRS), a respeito da evolução do conhecimento desenvolvido no curso para o desempenho da profissão de Engenheiro de Software. Foi conduzido um Survey com participação de alunos matriculados nas disciplinas da AGES em 2017, no $2^{\circ}$ semestre. Os resultados evidenciam a importância da AGES para complementar a formação técnica dos alunos com o exercício das habilidades não-técnicas, em especial Comunicação e Proatividade. Por outro lado, este trabalho foca em diferentes aspectos de um curso de ES em dois ciclos.

Neste sentido, este artigo difere-se dos demais por identificar e discutir os desafios, as percepções e as limitações dos discentes de uma graduação em ES, em dois ciclos. Discutiu-se também estratégias e orientações buscando resolver os problemas identificados.

\section{METODOLOGIA}

Neste trabalho foi adotado um procedimento metodológico de caráter quali-quantitativo, baseado na coleta, organização e análise de dados obtidos através de um Survey realizado com discentes de um curso de graduação em ES, no formato de dois ciclos. Como instrumento de coleta de dados foram aplicados dois questionários online. A seguir são descritos o planejamento, a execução e os procedimentos de análise adotados neste estudo.

\subsection{Planejamento}

Para compreender as causas que levam os discentes a evadirem de um curso de ES no formato de dois ciclos e de não prosseguirem à graduação ofertada no $2^{\circ}$ ciclo, bem como compreender aspectos relacionados às dificuldades no processo de ensino-aprendizagem, foram definidas quatro Questões de Pesquisa (QPs) específicas para conduzir este estudo:

$Q P_{1}$ : Quais as principais dificuldades percebidas pelos discentes no $1^{\circ}$ ciclo de uma graduação em ES?

$Q P_{2}$ : Quais as principais dificuldades percebidas pelos discentes no $2^{\circ}$ ciclo de uma graduação em ES?

$Q P_{3}$ : Qual a percepção dos discentes acerca do $1^{\circ}$ ciclo de uma graduação em ES? 
$Q P_{4}$ : Qual a percepção dos discentes acerca do $2^{\circ}$ ciclo de uma graduação em ES?

Desse modo, a $Q P_{1}$ busca identificar os principais desafios enfrentados pelos discentes no $1^{\circ}$ ciclo do curso, em relação a metodologias, formas de avaliação, comunicação com os docentes e uso de ferramentas de software. A $Q P_{2}$ investiga os principais desafios dos discentes, no $2^{\circ}$ ciclo do curso, avaliando se a maturidade adquirida no $1^{\circ}$ ciclo minimiza possíveis problemas relacionados às metodologias, formas de avaliação e comunicação com os docentes. As $Q P_{3}$ e $Q P_{4}$ buscam identificar a percepção referente à (in)satisfação dos discentes em relação às estratégias de ensino adotadas pelos docentes, ao alinhamento com demandas do mercado de trabalho e a outros aspectos relacionados à formação acadêmica-profissional dos discentes.

Para responder as questões de pesquisa foram elaborados dois questionários online ${ }^{1}$, com questões objetivas e subjetivas. O primeiro questionário foi destinado aos discentes com matrícula ativa no $1^{\circ}$ ciclo da graduação em ES; e o segundo questionário, aos discentes com matrícula ativa no $2^{\circ}$ ciclo da referida graduação. Para participar deste estudo, os discentes deveriam ter a matrícula ativa em um dos dois ciclos do curso de ES da UFERSA-CMPF.

As questões elencadas para os Surveys foram baseadas na classificação em quatro grupos proposta por Ferreira et al. (2018), que buscam identificar os tópicos emergentes e dificuldades no ensino de ES no Brasil. As questões referentes a disciplinas incluiu apenas aquelas relacionadas à área de ES, elencadas na explanação da questão, excluindo componentes, como Cálculo, Física e Sociologia

\subsection{Execução}

A coleta e análise dos dados foram processadas no período de maio a setembro de 2020. Os questionários foram enviados aos discentes, de forma automática, através do sistema acadêmico chamado de Sistema Integrado de Gestão de Atividades Acadêmicas (SIGAA). No total, foram obtidas 86 respostas dos discentes matriculados no $1^{\circ}$ ciclo e no $2^{\circ}$ ciclo desta graduação, equivalente a $19,36 \%$ dos discentes com matrícula ativa nos dois ciclos no período em que esta pesquisa foi realizada. Dentre estes discentes, 79 estão matriculados no $1^{\circ}$ ciclo (equivalente a $19,81 \%$, do total de NA neste ciclo) e 7 , matriculados no $2^{\circ}$ ciclo (equivalente a $70 \%$, do total de NA neste ciclo). Para mais detalhes consultar a Tabela 1. O Survey com os discentes do $2^{\circ}$ ciclo incluiu apenas aqueles de ES porque o estudo está focado, especificamente, nesta modalidade de graduação em dois ciclos. O curso de EC inclui discentes com outras características, como o interesse em hardware e automação.

Com os questionários foi possível obter informações sobre: 1) dados gerais dos discentes; 2) disciplinas cursadas; 3) infraestrutura utilizada no processo de aprendizagem; 4) informações sobre o ensino; 5) impactos observados na execução de disciplinas e 6) nível de estresse discente. Para preservar a identidade dos discentes, as informações dos relatórios de dados foram anonimadas.

\subsection{Procedimentos de Análise}

A análise dos dados foi conduzida em caráter quantitativo e qualitativo [21, 22]. A análise quantitativa foi baseada nas respostas fornecidas por meio da Escala Likert, com itens de 1 a 5 (1 = Discordo

\footnotetext{
${ }^{1}$ Acesso aos questionários aplicados no Survey: https://cutt.ly/vgjP7Ef.
}

Totalmente, $2=$ Discordo, $3=$ Neutro, $4=$ Concordo, $5=$ Concordo Totalmente). Ademais, uma análise qualitativa foi aplicada nas respostas das questões subjetivas, que caracterizaram informações complementares dadas às questões objetivas. A análise qualitativa foi utilizada na Seção 6 para detalhar as escolhas dos discentes.

\section{RESULTADOS OBTIDOS}

Os resultados coletados a partir dos questionários com os discentes do $1^{\circ}$ e $2^{\circ}$ ciclos são apresentados, respectivamente, nas Seções 5.1 e 5.2, a seguir. Mais informações e detalhes dos resultados, como dados brutos e gráficos, são disponibilizados em uma página pública online $e^{2}$.

\subsection{Survey com os Discentes do $1^{\circ}$ Ciclo}

No Survey com os discentes do $1^{\circ}$ ciclo foram identificados aspectos relacionados (i) ao perfil dos participantes; (ii) às dificuldades encontradas nas disciplinas obrigatórias e específicas do curso; (iii) à percepção sobre o formato de dois ciclos do curso; (iv) ao currículo do curso; e (v) a relação entre o curso e o mercado de trabalho.

5.1.1 Caracterização dos Participantes. No tocante ao gênero dos participantes, a maioria deles informou ser do sexo masculino $(60,8 \%)$. O resultado apresentado reflete a realidade, ainda observada nos cursos de TI, cujas pesquisas indicam que grande parte da população discente e ativa no mercado de trabalho ainda é predominantemente masculina [23, 24]. As faixas etárias que predominaram foram de 20 anos ou menos e de 21 a 25 anos, indicadas por $45,6 \%$ e $39,2 \%$ dos discentes, respectivamente.

Em relação à infraestrutura, 88,6\% dos discentes possuem computador próprio e todos dispõem de smartphone. As frequências de uso de smartphones mais citadas foram diariamente $(62,0 \%) \mathrm{e}$ frequentemente $(32,9 \%)$. Todos possuem acesso à Internet fora da UFERSA-CMPF, seja nas suas próprias residências $(94,9 \%)$ ou em outros ambientes $(15,2 \%)$, incluindo as citações em ambos os casos.

Dentre os discentes, 87,3\% informaram ter formação básica em escolas públicas e representam todos os PLs: 2015.2 - 3,8\%; 2016.1 - 7,6\%; 2016.2 - 5,1\%; 2017.1 - 10,1\%; 2017.2 - 5,1\%; 2018.1 - 10,1\%; 2018.2 - 11,4\%; 2019.1 - 19,0\%; 2019.2 - 8,9\%; e 2020.1 - 17,7\%.

Os discentes indicaram possuir pouco conhecimento sobre os cursos de $1^{\circ}$ e $2^{\circ}$ ciclo antes de ingressar na instituição. Para o $1^{\circ}$ ciclo, 32,9\% e 30,4\% informaram conhecer "nada" e "pouco" sobre o curso, respectivamente. Já para o $2^{\circ}$ ciclo, a resposta "nada" recebeu $40,5 \%$ e "pouco" ficou com $29,1 \%$ dos votos.

Referente à motivação para escolher um curso na área de TI, $38,0 \%$ dos discentes informaram a abrangência do mercado de trabalho. Algo preocupante é que 16,5\% deles informaram ingressar no curso porque "foi o que deu para passar dada a nota do ENEM".

Em termos de experiência com linguagens de programação antes de ingressar no curso, 75,9\% dos discentes afirmaram não ter experiência, enquanto 13,9\% afirmaram até um ano de experiência. Outros $15,2 \%, 12,7 \%$ e $10,1 \%$ adquiriram-na em cursos técnicos, videoaulas no YouTube e cursos na Internet, respectivamente.

5.1.2 Dificuldades nas Disciplinas Obrigatórias do $1^{\circ}$ Ciclo. Em resposta à $Q P_{1}$, as dificuldades foram classificadas em quatro grupos, relacionados à pedagogia, aos recursos materiais, à motivação para

${ }^{2}$ Acesso aos resultados detalhados do Survey: https://cutt.ly/rjAQiyV. 
aprendizado e ao conteúdo lecionado. A seguir são destacadas as respostas mais informadas pelos discentes:

- Pedagogia: desenvolver a parte prática dos conteúdos estudados $(31,6 \%)$, conciliar teoria e prática $(30,4 \%)$ e a falta de exemplos práticos (29,1\%). 22,8\% não apontaram dificuldades.

- Recursos materiais: limitação de equipamentos nos laboratórios $(22,8 \%)$, indisponibilidade de ferramentas gratuitas $(17,7 \%)$ e falta de recursos bibliográficos para assuntos recentes (16,5\%). 57,0\% não apontaram dificuldades.

- Motivação para aprendizado: dificuldade em programar $(35,4 \%)$, uso das metodologias de ensino aplicadas nos componentes $(34,2 \%)$, a falta de conhecimento dos fundamentos de informática $(17,7 \%)$ e a dificuldade no entendimento dos requisitos (17,7\%). 20,3\% não apontaram dificuldades.

- Conteúdo lecionado: conteúdo muito teórico $(41,8 \%)$, conteúdo extenso $(31,6 \%)$ e constante atualização da área $(6,3 \%)$ $27,8 \%$ apontaram não encontrar dificuldades.

5.1.3 Dificuldades com Disciplinas do Eixo Específico de ES no $1^{\circ}$ Ciclo. Algumas disciplinas do $1^{\circ}$ ciclo são específicas de ES. Embora, a maioria dos discentes tenha afirmado ainda não as ter cursado $(65,8 \%)$, identificou-se nas demais respostas algumas dificuldades, que também foram agrupadas, de modo a responder à $Q P_{1}$.

- Pedagogia: falta de exemplos práticos $(8,9 \%)$ e desenvolver a parte prática $(7,6 \%)$. Alguns discentes informaram não encontrar dificuldades relacionadas à pedagogia $(10,1 \%)$.

- Recursos materiais: falta de recursos bibliográficos para assuntos recentes $(10,1 \%)$ e indisponibilidade de ferramentas gratuitas (6,3\%). Alguns discentes informaram não encontrar dificuldades relacionadas aos recursos materiais $(15,2 \%)$.

- Motivação para aprendizado: metodologia de ensino na disciplina $(10,1 \%)$ e dificuldade no entendimento dos requisitos $(10,1 \%)$. Alguns discentes informaram não encontrar dificuldades relacionadas à motivação $(11,4 \%)$.

- Conteúdo lecionado: conteúdo muito teórico $(10,1 \%)$ e conteúdo extenso $(10,1 \%)$. Alguns informaram não encontrar dificuldades relacionadas ao conteúdo lecionado $(10,1 \%)$.

5.1.4 Percepção sobre o $1^{\circ}$ Ciclo. O curso de ES na UFERSA-CMPF pode ser visto como um curso: (i) independente, que corresponde apenas ao $2^{\circ}$ ciclo; ou (ii) único e integrado, dividido em duas partes - em que a primeira é constituída pelo $1^{\circ}$ ciclo. Para os discentes, predomina a visão ii $(70,9 \%)$.

Em relação à motivação pela escolha do curso, destacaram-se: o mercado de trabalho (57,3\%), a familiaridade com alguma disciplina na área $(18,7 \%)$ e a própria área de ES (13,3\%). Considerando a opção de escolha do discente ao concluir o $1^{\circ}$ ciclo, $51,9 \%$ dos discentes informaram ter interesse em ingressar no mercado de trabalho, enquanto outros pretendem cursar a graduação do $2^{\circ}$ ciclo em ES $(51,9 \%)$ e, outros ainda, cursar a graduação do $2^{\circ}$ ciclo em EC $(31,6 \%)$. a) $1^{\circ} \boldsymbol{e} 2^{\circ}$ ciclo. Na Figura 1 é sintetizada a percepção dos discentes sobre alguns aspectos do curso, como infraestrutura, docentes, metodologia de ensino e conhecimento de projetos de ensino, pesquisa e extensão. Em relação à infraestrutura dos cursos foi percebida uma inclinação para satisfação $(29,1 \%)$ e total satisfação $(10,1 \%)$ para o $1^{\circ}$ ciclo e também para o $2^{\circ}$ ciclo - satisfação $(27,8 \%)$ e total satisfação $(7,6 \%)$.
Figura 1: Percepção sobre diferentes aspectos dos ciclos

\begin{tabular}{|c|c|c|c|c|}
\hline Infraestrutura $1^{\circ}$ ciclo & & $, 6 \% 20,3 \%$ & $32,9 \%$ & $29,1 \% \quad 10,1 \%$ \\
\hline Infraestrutura $2^{\circ}$ ciclo & & $3,9 \% \quad 13,9 \%$ & $41,8 \%$ & $27,8 \%$ \\
\hline Professores $1^{\circ}$ ciclo & & $3,8 \% 16,5 \%$ & $34,2 \%$ & $31,6 \%$ \\
\hline Professores $2^{\circ}$ ciclo & & $5,1 \% \quad 12,7 \%$ & $36,7 \%$ & $34,2 \%$ \\
\hline Metodologia de ensino $1^{\circ}$ ciclo & $11,4 \%$ & $24,1 \%$ & $38,0 \%$ & $15,2 \% \quad 11,4 \%$ \\
\hline Metodologia de ensino $2^{\circ}$ ciclo & $8,9 \%$ & $17,7 \%$ & $48,1 \%$ & \begin{tabular}{|l|l|}
$15,2 \%$ & $10,1 \%$ \\
\end{tabular} \\
\hline
\end{tabular}

Sobre os professores, os discentes apresentaram predisposição para satisfação $(31,6 \%)$ e total satisfação $(13,9 \%)$ para aqueles do $1^{\circ}$ ciclo, estando também inclinados à satisfação e total satisfação para aqueles do $2^{\circ}$ ciclo - satisfação $(34,2 \%)$ e total satisfação $(11,4 \%)$.

No tocante às metodologias de ensino foi notada uma predisposição para insatisfação $(24,1 \%)$ e total insatisfação $(11,4 \%)$ para o $1^{\circ}$ ciclo e de neutralidade para o $2^{\circ}$ ciclo. Referente aos projetos desenvolvidos nos cursos, os dados são mostrados na Figura 2.

Figura 2: Percepção sobre projetos

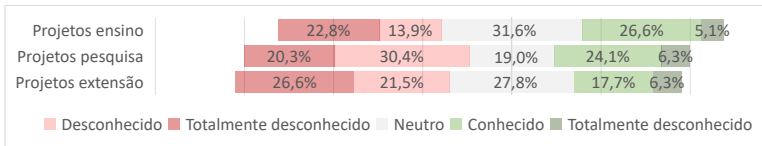

Há uma inclinação de desconhecimento e total desconhecimento com todos os tipos de projetos, sendo essa de $13,9 \%$ e $22,8 \%$, respectivamente para os projetos de ensino e de $21,5 \%$ e $26,6 \%$ de desconhecimento e total desconhecimento, nesta ordem, para aqueles de extensão. Já para os projetos de pesquisa essas inclinações foram de $30,4 \%$ e $20,3 \%$, respectivamente.

Sobre os Grupos de Pesquisa (GPs) dos cursos, foi identificado que $77,2 \%$ dos discentes não participam de nenhum grupo. Na Tabela 2 são vistos dados dos discentes sobre a participação nos GPs - Laboratório de Pesquisa em Informática na Educação (LABIE), Grupo de Pesquisa em Sistemas Críticos de Segurança (GPSiCS), Laboratório de Análise de Sinais Biomédicos (LASBIO) e Laboratório de Inovações em Software (LIS) - e também o conhecimento dos GPs e o interesse em integrar em algum dos GPs.

Tabela 2: Percepção dos Discentes do $1^{\circ}$ ciclo sobre os GPs

\begin{tabular}{l|l|l|l|l}
\hline & LABIE & GPSiCS & LASBIO & LIS \\
\hline Participação & $11,4 \%$ & $6,3 \%$ & $1,3 \%$ & $5,1 \%$ \\
Conhecimento & $64,6 \%$ & $41,8 \%$ & $41,8 \%$ & $26,6 \%$ \\
Interesse & $41,8 \%$ & $7,6 \%$ & $27,8 \%$ & $3,8 \%$ \\
\hline
\end{tabular}

Percebeu-se também que os GPs que atuam com Inteligência Artificial (IA) interessam mais aos discentes (82,3\%). Outros interesses mais citados foram jogos $(64,6 \%)$ e dispositivos móveis $(57,0 \%)$.

b) Currículo do $1^{\circ}$ Ciclo. A percepção dos discentes do currículo do $1^{\circ}$ ciclo é mostrada na Figura 3. Destacaram-se aspectos relacionados ao currículo, horários, quantidade de disciplinas, estágio supervisionado e Trabalho de Conclusão de Curso (TCC). 
Figura 3: Percepção dos discentes sobre o currículo do ciclos

\begin{tabular}{|c|c|c|c|}
\hline Currículo do $1^{\circ}$ ciclo & $15,2 \% \quad 24,1 \%$ & $32,9 \%$ & $20,3 \% 7,6 \%$ \\
\hline Currículo do $2^{\circ}$ ciclo & $6,3 \% 17,7 \%$ & $40,5 \%$ & $27,8 \% \quad 7,6 \%$ \\
\hline Horários do $1^{\circ}$ ciclo & $17,7 \% \quad 24,1 \%$ & $22,8 \%$ & $25,3 \% \quad 10,1 \%$ \\
\hline Horários do $2^{\circ}$ ciclo & $13,9 \% 17,7 \%$ & $35,4 \%$ & $20,3 \% 11,4 \%$ \\
\hline Quantidade disciplinas no $1^{\circ}$ ciclo & $11,4 \% \quad 16,5 \%$ & $38,0 \%$ & $25,3 \% \quad 8,9 \%$ \\
\hline Quantidade disciplinas no $2^{\circ}$ ciclo & $6,3 \% 11,4 \%$ & $44,3 \%$ & $26,6 \% \quad 11,4 \%$ \\
\hline Estágio supervisionado do $1^{\circ}$ ciclo & $\begin{array}{ll}7,6 \% & 26,6 \%\end{array}$ & $34,2 \%$ & $25,3 \% \quad 5,1 \%$ \\
\hline Estágio supervisionado do $2^{\circ}$ ciclo & $\begin{array}{ll}6,3 \% & 25,3 \%\end{array}$ & $39,2 \%$ & $22,8 \% 5,1 \%$ \\
\hline Trabalho de conclusão do $1^{\circ}$ ciclo & $7,6 \% \quad 11,4 \%$ & $36,7 \%$ & $26,6 \% \quad 16,5 \%$ \\
\hline Trabalho de conclusão do $2^{\circ}$ ciclo & $8,9 \% \quad 10,1 \%$ & $44,3 \%$ & $25,3 \% \quad 11,4 \%$ \\
\hline
\end{tabular}

De modo geral, os discentes tenderam a apresentar insatisfação $(24,1 \%)$ e total insatisfação $(15,2 \%)$ com a matriz curricular do $1^{\circ}$ ciclo e satisfação $(27,8 \%)$ e total satisfação $(7,6 \%)$ com a do $2^{\circ}$ ciclo.

Referente aos horários das disciplinas, os discentes demonstraram inclinação para insatisfação $(24,1 \%)$ e total insatisfação $(17,7 \%)$ para os horários do $1^{\circ}$ ciclo e tenderam levemente para satisfação $(20,3 \%)$ e total satisfação $(11,4 \%)$ para aqueles do $2^{\circ}$ ciclo.

A quantidade de disciplinas apresentou inclinação de satisfação $(25,3 \%)$ e total satisfação $(8,9 \%)$ para o $1^{\circ}$ ciclo e também para o $2^{\circ}$ ciclo - satisfação $(26,6 \%)$ e total satisfação $(11,4 \%)$. O estágio supervisionado apresentou uma leve tendência de insatisfação $(26,6 \%)$ e total insatisfação $(7,6 \%)$ no $1^{\circ}$ ciclo, assim como no $2^{\circ}$ ciclo - insatisfação $(25,3 \%)$ e total insatisfação $(6,3 \%)$. Já o TCC é visto positivamente nos dois ciclos, com uma predisposição de satisfação de $26,6 \%$ e de total satisfação de $16,5 \%$ para o $1^{\circ}$ ciclo e de satisfação de $25,3 \%$ e de total satisfação de $11,4 \%$ para o $2^{\circ}$ ciclo.

A disciplina Projeto e Design de Interfaces, do eixo específico de ES, foi citada em 30,4\% das respostas, como a área desejada para atuar. Seguido das disciplinas Projeto Detalhado de Software $(24,1 \%)$, Planejamento e Gerenciamento de Projetos (24,1\%). Alguns discentes $(49,4 \%)$ não opinaram sobre elas por não cursá-las.

Já referente às áreas do eixo profissionalizante, $40,5 \%$ gostariam de atuar com Banco de Dados, 36,7\% com Engenharia de Software e 30,4\% com Programação Orientada a Objetos. Alguns discentes $(25,3 \%)$ não conseguiram opinar sobre elas por não cursá-las.

c) Sobre o Mercado de Trabalho. No geral, os discentes divergiram sobre o alinhamento do $1^{\circ}$ e $2^{\circ}$ ciclo com o mercado de trabalho. Percebeu-se uma tendência de desalinhamento $(21,5 \%)$ e total desalinhamento $(21,5 \%)$ para o $1^{\circ}$ ciclo e uma tendência de alinhamento $(29,1 \%)$ e total alinhamento $(7,6 \%)$ para o $2^{\circ}$ ciclo, conforme Figura 4.

\section{Figura 4: Alinhamento com o mercado de trabalho}

$$
\begin{aligned}
& \text { Mercado e } 1^{\circ} \text { ciclo } \\
& \text { Mercado e } 2^{\circ} \text { ciclo } \\
& \begin{array}{|l|l|l|l|l}
\hline 21,5 \% & 21,5 \% & 25,3 \% & 24,1 \% & 7,6 \% \\
\hline
\end{array} \\
& \begin{array}{lll}
6 \% & 17,7 \% \quad 38,0 \%
\end{array} \\
& 29,1 \% \quad 7,6 \% \\
& \text { Desalinhado } \quad \text { Totalmente desalinhado Neutro } \quad \text { Alinhado } \quad \text { Totalmente alinhado }
\end{aligned}
$$

No período de realização do Survey, $87,3 \%$ dos discentes do $1^{\circ}$ ciclo informaram não estar trabalhando ou estagiando. Outros 3,8\% estão apenas estagiando e 2,5\% estão trabalhando. Entre os que já estão no mercado de trabalho, o cargo "Desenvolvedor Júnior" foi o mais citado (7,6\%), seguido pelo de "Designer" (3,8\%).

Considerando as áreas de interesse para atuação profissional e seguindo as indicações do SWEBOK [16], os discentes elencaram Projeto e Construção de Software como as mais promissoras, ambas com o quantitativo de $26,6 \%$ das respostas. Seguidas pela área de Teste (19,0\%), Requisitos (16,7\%) e Manutenção de Software (16,7\%). Outros 50\% não opinaram sobre esse tema por ainda não cursar as disciplinas relacionadas a cada área apresentada.

\subsection{Survey com os Discentes do $2^{\circ}$ Ciclo}

No Survey com os discentes do $2^{\circ}$ ciclo da graduação em ES foram identificados (i) aspectos relacionados ao perfil social dos participantes da pesquisa; (ii) dificuldades dos discentes ao cursar as disciplinas do $2^{\circ}$ ciclo; (iii) percepção sobre a graduação em ES; (iv) satisfação com a graduação em ES; e, por fim, (v) percepção acerca do mercado de trabalho.

5.2.1 Caracterização dos Participantes. Todos os participantes informaram ser do sexo masculino e também da faixa etária compreendida entre 21 a 25 anos. Assim como dispõem de computador, aparelho celular, possuem acesso à Internet e são provenientes de escolas públicas. Dentre os participantes, $85,7 \%$ utilizam diariamente e 14,3\% afirmaram fazer uso frequente de dispositivos móveis.

As respostas deste Survey vieram de discentes com matrícula ativa no PL 2020.1 (57,1\%) e 2019.1 (42,9\%). Embora os discentes do $2^{\circ}$ ciclo já tenham concluído um período de, em média, 3 anos de formação na graduação de $1^{\circ}$ ciclo, apenas $28,6 \%$ afirmaram conhecer bem o curso de ES antes de ingressar, enquanto outros $57,1 \%$ informaram conhecer razoavelmente e $14,3 \%$, conhecer pouco.

Todos informaram as oportunidades profissionais na área como uma das motivações para escolher o curso, 85,7\% afirmaram a identificação com disciplinas e 57,1\% afirmaram familiaridade na área.

Em relação ao domínio de linguagens de programação, os discentes destacaram: a linguagem $C$, conhecida por todos os participantes; e as linguagens Java, HTML + CSS e JavaScript, ambas representadas pelo percentual de 85,7\%. Já as linguagens/frameworks que os discentes desejam aprender são Python (28,6\%), Angular, Go, Swift, Dart/Flutter e JavaScript (com o mesmo percentual, 14,3\%). Os discentes afirmaram ainda, usar recursos extracurriculares para aprender novas linguagens de programação, como videoaulas do YouTube (100\%), cursos na Internet $(71,4 \%)$ e uso de livros $(42,9 \%)$.

5.2.2 Dificuldades nas Disciplinas do Curso. Em relação às dificuldades nas disciplinas do $2^{\circ}$ ciclo foram destacadas as seguintes:

- Pedagogia: conexão com outras disciplinas (42,9\%), diversidade das tecnologias associadas $(28,6 \%)$. A maioria não encontrou dificuldades $(57,1 \%)$.

- Recursos Materiais: falta de bibliografia para assuntos recentes $(42,9 \%)$, indisponibilidade de ferramentas gratuitas $(14,3 \%)$. A maioria não encontrou dificuldades $(71,4 \%)$.

- Motivação para Aprendizado: metodologias de ensino (28,6\%). A maioria não encontrou dificuldades $(71,4 \%)$.

- Conteúdo Lecionado: conteúdos muito teóricos (28,6\%), constante atualização da área $(28,6 \%)$, conteúdo extenso $(14,3 \%)$. A maioria não encontrou dificuldades $(42,9 \%)$. 
5.2.3 Percepção sobre o Curso. Para os discentes, a graduação em ES é compreendida como um curso separado, dividido em dois ciclos $(85,7 \%)$. Na Figura 5 ilustra-se a percepção dos discentes sobre a infraestrutura, docentes e metodologia de ensino do curso.

\section{Figura 5: Percepção dos discentes sobre aspectos do curso}

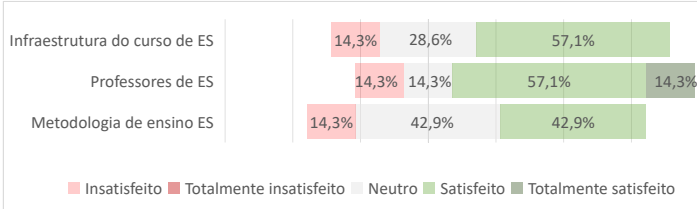

Sobre a infraestrutura do curso, $57,1 \%$ estão satisfeitos, $28,6 \%$ neutros e $14,3 \%$ insatisfeitos. A satisfação em relação ao uso dos equipamentos dos laboratórios ficou distribuída com a mesma pontuação $(28,6 \%)$ para as opções "Sim", "Não" e "Estou satisfeito".

Os discentes mostraram satisfação com os docentes do curso satisfação de $57,1 \%$ e total satisfação de $14,3 \%$. Também houve inclinação de satisfação $(42,9 \%)$ para as metodologias de ensino. As que interessaram mais os discentes foram palestras com profissionais da indústria de software (85,7\%), projetos interdisciplinares $(85,7 \%)$, mais aulas práticas $(71,4 \%)$ e visitas técnicas $(71,4 \%)$.

Sobre os GPs do curso, identificou-se que $42,9 \%$ dos discentes não participam de nenhum GP e 71,4\% não tem interesse em integrar um GP. A Tabela 3 apresenta mais informações sobre a participação, o conhecimento e o interesse dos discentes em integrar um GP.

\section{Tabela 3: Percepção dos discentes do $2^{\circ}$ ciclo sobre os GPs}

\begin{tabular}{l|l|l|l|l}
\hline & LABIE & GPSiCS & LASBIO & LIS \\
\hline Participação & $28,6 \%$ & $28,6 \%$ & $0,0 \%$ & $0,0 \%$ \\
Conhecimento & $100,0 \%$ & $71,4 \%$ & $85,7 \%$ & $100,0 \%$ \\
Interesse & $14,3 \%$ & $0,0 \%$ & $0,0 \%$ & $28,6 \%$ \\
\hline
\end{tabular}

Percebeu-se também que os GPs que atuam com Dispositivos Móveis $(100 \%)$, Jogos (85,7\%), Inteligência Artificial (71,4\%) e Realidade Virtual $(57,1 \%)$ despertam mais interesse dos discentes.

Por fim, considerando a escolha do discente ao concluir o $2^{\circ}$ ciclo, o mercado de trabalho privado foi citado por todos eles. Enquanto o ingresso em uma pós-graduação foi informado por 71,4\% e seguir carreira como freelancer foi informado por $28,6 \%$ dos discentes.

a) Satisfação com o $2^{\circ}$ Ciclo. Todos os discentes indicaram conhecer a matriz curricular do curso e estão satisfeitos com a quantidade de disciplinas por PL. Sobre a satisfação com as disciplinas ofertadas, $57,1 \%$ deles estão insatisfeitos, enquanto $28,6 \%$ estão satisfeitos e $14,3 \%$ não souberam responder. Em relação ao estágio supervisionado, $42,9 \%$ estão satisfeitos, $42,9 \%$ não souberam responder e $14,3 \%$ estão insatisfeitos. A maioria deles estão satisfeitos com o TCC (85,7\%), enquanto $14,3 \%$ estão insatisfeitos.

As áreas de maior interesse dos discentes foram Desenvolvimento Web (71,4\%), Desenvolvimento para Dispositivos Móveis
(71,4\%), Metodologias Ágeis de Desenvolvimento (42,9\%) e Modelagem de Processos de Negócios (42,9\%).

b) Mercado de Trabalho. Os discentes entendem que o $2^{\circ}$ ciclo ainda está desalinhado com o mercado de trabalho (42,9\%), enquanto que $14,3 \%$ informaram o oposto e $42,9 \%$ não souberam responder.

No período de realização do Survey, $42,9 \%$ não estão estagiando ou trabalhando, $28,6 \%$ estão estagiando e $28,6 \%$ estão trabalhando. Dentre aqueles que estão trabalhando ou estagiando, $28,6 \%$ atuam como Desenvolvedor, $14,3 \%$ atuam como Arquiteto de Software e $14,3 \%$ como Freelancer. Alguns deles ainda se interessam em atuar como Desenvolvedor (71,4\%), Gerente de Projetos (14,3\%) ou Designer $(14,3 \%)$.

\section{DISCUSSÃO DOS RESULTADOS}

Nesta seção são respondidas as questões de pesquisa e apontadas estratégias para contornar dificuldades elencadas pelos discentes.

\subsection{Respostas às Questões de Pesquisa}

6.1.1 $Q P_{1}$. Quais as principais dificuldades percebidas pelos discentes no $1^{\circ}$ ciclo de uma graduação em ES? Identificaram-se dificuldades relacionadas à pedagogia, recursos materiais, ao aluno e ao conteúdo lecionado.

Em relação à pedagogia, percebeu-se que os discentes possuem dificuldades com as atividades teóricas das disciplinas. Para Portela et al. [8], os discentes preferem atividades práticas, como projetos com características similares àquelas do mercado de trabalho. Em estudo com docentes da UFERSA-CMPF, Leite et al. (2020) destacam que os docentes apontaram a falta de tempo $(40,0 \%)$, representação de escala de projetos reais e acadêmicos $(26,6 \%)$, conexão com outras disciplinas $(26,6 \%)$, tratar conteúdos de outras disciplinas $(26,6 \%)$ e ausência ou insuficiência de capacitação pedagógica como principais fatores dificultantes da pedagogia $(26,6 \%)$.

Outra dificuldade foi a limitação de equipamentos nos laboratórios. Isto acontece em algumas disciplinas específicas, principalmente àqueles envolvendo linguagens de programação, nos PLs iniciais. Nestes casos específicos, geralmente, há um elevado número de matriculas - os participantes pela primeira vez e repetentes. Logo, torna-se difícil ofertar uma infraestrutura que dê suporte a máquinas individuais para cada aluno. Diferentemente, as disciplinas do eixo específico do $2^{\circ}$ ciclo são ofertadas a partir do $4^{\circ}$ período, com redução nas matrículas, o que torna a infra-estrutura do $2^{\circ}$ ciclo mais adequada. Também há dificuldades de recursos materiais para assuntos recentes.A tecnologia evolui rapidamente e manter uma bibliografia atualizada com novos temas é uma tarefa árdua, impulsionada pela burocracia envolvida na aquisição de materiais. Conforme Leite et al. (2020), os docentes também citaram como dificuldades a falta de recursos bibliográficos para assuntos recentes $(33,3 \%)$ e limitação de equipamentos nos laboratórios de informática $(33,3 \%)$. Porém, o problema mais citado foi a indisponibilidade de ferramentas gratuitas, em alguns casos (46,7\%).

Existem dificuldades na motivação dos discentes. A dificuldade em programar é tida como o principal aspecto direcionado à motivação para cursar boa parte dos componentes curriculares específicos do $1^{\circ}$ ciclo. Os problemas com programação podem ser decorrentes do elevado número de participantes dos PLs iniciais. Algoritmos, 
por exemplo, não é um conteúdo difundido no ensino básico, fundamental e médio das escolas públicas ou privadas, fazendo do ensino superior o primeiro contato. Em Leite et al. (2020), os docentes também apontaram a dificuldade em programar como problema $(66,7 \%)$, mas o desinteresse do aluno (73,3\%) foi o fator mais citado. Para minimizar essas dificuldades, desenvolveram-se ações para entender o que leva à desmotivação [25, 26], para minimizar as dificuldades com programação [27, 28] e para motivar discentes [29].

Por fim, a metodologia de ensino e o entendimento dos requisitos de um sistema foram destacadas pelos discentes como dificuldades. Conteúdos muito teóricos e extensos foram as principais dificuldades dos discentes referente ao conteúdo lecionado, nas disciplinas do $1^{\circ}$ e $2^{\circ}$ ciclo. Outras dificuldades mais específicas foram apontadas, tais como: a quantidade excessiva de componentes curriculares da área matemática; a ausência de um material adequado à acessibilidade; o uso de linguagens de programação mais modernas nas ementas das disciplinas; e a necessidade de conciliar obrigações estudantis com vida pessoal. No tocante aos docentes, Leite et al. (2020) destacou como dificuldades referentes à este tópico o conteúdo muito teórico $(40,0 \%)$ e o conteúdo extenso (26,7\%).

6.1.2 QP 2 . Quais as principais dificuldades percebidas pelos discentes no $2^{\circ}$ ciclo de uma graduação em ES? Assim como no $1^{\circ}$ ciclo, elencaram-se dificuldades com a pedagogia, recursos materiais, aluno e conteúdo lecionado.

Os discentes citaram a conexão com outras disciplinas como a maior dificuldade referente à pedagogia, diferenciando-se das respostas daqueles do $1^{\circ}$ ciclo (i.e., citaram mais o desenvolvimento da parte prática). Em Leite et al. (2020), os docentes citaram a falta de tempo $(33,3 \%)$ e a representação de escala de projetos reais e acadêmicos $(33,3 \%)$ como principais dificuldades neste contexto.

A falta de recursos bibliográficos para assuntos recentes foi citada com principal dificuldade para os recursos materiais. A limitação de equipamentos nos laboratórios não foi citada pelos discentes. Isso pode ser explicado pelo volume de discentes que atualmente é muito menor no $2^{\circ}$ ciclo, facilitando a distribuição de espaços de laboratórios para os componentes que precisam utilizá-lo. Em Leite et al. (2020), a indisponibilidade, em alguns casos, de ferramentas gratuitas $(33,3 \%)$ foi a mais apontada pelos docentes.

A metodologia de ensino, assim como no $1^{\circ}$ ciclo, continua citada como uma dificuldade para a motivação para o aprendizado. O conteúdo muito teórico e a constante atualização da área foram citados como dificultantes do conteúdo lecionado, aspecto similar ao mencionado pelos discentes do $1^{\circ}$ ciclo. Em Leite et al. (2020), os docentes citaram como dificuldades referente ao aluno a dificuldade em programar $(33,3 \%)$ e a falta de maturidade técnica $(22,2 \%)$. Referente ao conteúdo, as principais dificuldades citadas pelos docentes foram conteúdo extenso $(22,2 \%)$ ou muito teórico $(22,2 \%)$.

6.1.3 $Q P_{3}$. Qual a percepção dos discentes acerca do $1^{\circ}$ ciclo de ES? No tocante à estrutura curricular, os alunos, em sua maioria, veem o curso de ES como um curso único, dividido em duas partes. Assim, algumas possibilidades são vislumbradas, tais como a possibilidade de obter uma graduação com o $1^{\circ}$ ciclo, rapidamente (em três anos); a possibilidade de escolher outro curso no $2^{\circ}$ ciclo, ao invés de apenas ES; obter uma base para as disciplinas do $2^{\circ}$ ciclo a partir da estrutura curricular do curso de $1^{\circ}$ ciclo; a possibilidade de uma formação completa e mais robusta, com dois diplomas de graduação; e a postergação de decisões, mesmo após ingressar no ensino superior. Também há discentes que entendem a graduação em ES como um curso de $2^{\circ}$ ciclo independente, em virtude de o $2^{\circ}$ ciclo apresentar disciplinas específicas para a área de ES e, ao ser mais específico, tornar o currículo do curso "mais leve".

O mercado de trabalho foi a motivação mais citada pelos discentes para a escolha do $2^{\circ}$ ciclo em ES. Bem como após concluir o $1^{\circ}$ ciclo boa parte dos discentes pretendem ir para o mercado de trabalho ou cursar o $2^{\circ}$ ciclo em ES. Nesse sentido, destaca-se a importância de aspectos profissionais nas disciplinas, tanto no $1^{\circ}$ ciclo, para preparar para o mercado profissional, quanto no $2^{\circ}$ ciclo, para propiciar o aprofundamento em competências mais específicas.

No geral, os discentes estão satisfeitos com a infraestrutura e com os docentes, em ambos os ciclos. No entanto, existe uma insatisfação com as metodologias de ensino aplicadas. Neste sentido, destacam-se algumas percepções e sugestões dos discentes, tais como: (i) a inserção de mais atividades práticas e próximas à vivência no mercado de trabalho; (ii) a utilização de linguagens de programação mais modernas nas ementas das disciplinas; (iii) projetos multidisciplinares entre os componentes curriculares; (iv) maior flexibilidade dos professores para com discentes; (v) adoção de metodologias ativas; e (vi) o uso de tecnologias de apoio ao ensino. Para as disciplinas específicas de ES foram indicadas a adoção de atividades práticas voltadas para o mercado de trabalho, além de projetos interdisciplinares entre os componentes curriculares e maior aplicação das metodologias ágeis de desenvolvimento.

Os projetos de ensino, pesquisa e extensão, em geral, são desconhecidos no $1^{\circ}$ ciclo, principalmente os de pesquisa e extensão. $\mathrm{O}$ LABIE figura entre os GPs que os discentes mais participam, conhecem e se interessam em participar, o que pode ser explicado por ele desenvolver várias ações nos PLs iniciais do curso, alcançando todos os ingressantes, e por executar diversos projetos de ensino, pesquisa e extensão, simultaneamente.

Dentre os motivos para ingressar em um GP, destacaram-se: (i) curiosidade pela área e atuação em um GP; (ii) aquisição de conhecimentos e o aprimoramento na área do GP; (iii) desejo de ajudar a instituição; (iv) familiaridade com área de pesquisa do GP; (v) experiências prévias positivas da participação em GPs; (vi) preparação pessoal e profissional; (vii) e contribuição com o mercado de trabalho. As áreas de pesquisa de maior interesse dos discentes foram IA, Jogos e Desenvolvimento para Dispositivos Móveis.

Currículo do $1^{\circ}$ e $2^{\circ}$ Ciclo. Os resultados indicam a insatisfação dos discentes com o currículo do $1^{\circ}$ ciclo e a satisfação com aquele do $2^{\circ}$ ciclo. Estes dados podem ser explicados por o $1^{\circ}$ ciclo possibilitar diferentes opções de formação, sem tendência para uma delas, diferentemente do $2^{\circ}$ ciclo, que foca apenas em ES. A quantidade de disciplinas é vista como adequada nos dois ciclos, porém, os discentes apontaram insatisfação com os horários do $1^{\circ}$ ciclo e neutralidade com aqueles do $2^{\circ}$ ciclo. Isto pode ser explicado por o $2^{\circ}$ ciclo conter uma carga horária semestral menor e mais flexível, permitindo a organização de horários para outras atividades (e.g. estágio, pós-graduação, trabalho). Isto normalmente é inviabilizado no $1^{\circ}$ ciclo, devido à alta carga horária semestral do curso. Já o estágio supervisionado é visto como levemente inadequado nos dois ciclos e o TCC, como adequado em ambos os ciclos.

Preferências por Disciplinas. Projeto e Design de Interfaces, Projeto Detalhado de Software e Planejamento e Gerenciamento de 
Projetos foram as disciplinas que mais interessam os discentes, referentes àquelas específicas de ES no $1^{\circ}$ ciclo. Já da lista de componentes do eixo profissionalizante no $1^{\circ}$ ciclo, as mais citadas foram Banco de Dados e Engenharia de Software. Nesse sentido, nota-se uma ausência de componentes explicitamente voltados à programação. Este aspecto pode ser explicado pela quantidade de discentes dos PLs iniciais no Survey, que costumam apresentar maiores dificuldades em disciplinas voltadas para programação. Já em relação às disciplinas do $2^{\circ}$ ciclo, os discentes citaram aquelas de programação no mercado de trabalho, tais como Desenvolvimento Web e para Dispositivos Móveis. Este resultado sugere o foco em disciplinas mais próximas da atuação real dos discentes no mercado de trabalho, ao invés de conteúdos que são aplicados em contextos específicos, como a linguagem de programação $C$, atualmente estudada em alguns componentes curriculares.

Mercado de Trabalho. O $1^{\circ}$ ciclo é visto como uma formação desalinhada com o mercado de trabalho, segundo os discentes. Já o $2^{\circ}$ ciclo apresentou um resultado oposto. Este resultado pode ser explicado pela preparação mais geral do $1^{\circ}$ ciclo, uma vez que este atende a demandas distintas. Diferentemente do $2^{\circ}$ ciclo focado apenas em ES. A maioria dos discentes não está trabalhando ou estagiando. Este resultado é justificado por a maioria dos respondentes estarem cursando os PLs iniciais. Entre os discentes que estão trabalhando são predominantes as carreiras de desenvolvedor e designer - explicando o amplo interesse citado nesta área.

Tópicos Emergentes. Referente aos tópicos de interesse dos discentes do $1^{\circ}$ ciclo foram citados Big Data; mais disciplinas voltadas ao mercado de trabalho e à arquitetura de software; linguagens de programação "em alta" no mercado de trabalho; conteúdo voltado ao desenvolvimento Web e Mobile; conteúdos voltados a bancos de dados e segurança digital; desenvolvimento de Jogos Educacionais; utilização de ferramentas mais usadas no mercado de trabalho; disciplinas com foco em requisitos, manutenção, desenvolvimento e teste; e também temas relacionados a UX/UI Designer. Neste sentido, percebe-se nos discentes, um foco na atuação profissional.

6.1.4 QP. Qual a percepção dos discentes acerca do $2^{\circ}$ ciclo de ES? Os discentes do $2^{\circ}$ ciclo também entendem ES com um curso dividido em duas partes. Sustentam suas opiniões pelo BI possuir grande parte das disciplinas voltadas para trazer um panorama geral sobre temas, fornecendo uma visão mais aberta sobre as possibilidades e uma base para os conteúdos do $2^{\circ}$ ciclo. Os discentes que entendem ES como um curso separado compreendem que o $2^{\circ}$ ciclo apresenta uma visão mais específica da área, comparado ao $1^{\circ}$ ciclo.

As principais escolhas dos discentes após concluir o $2^{\circ}$ ciclo foram mercado de trabalho e pós-graduação. Resultado que indica a necessidade de ações mais direcionadas para estas linhas de atuação.

No geral, os discentes estão satisfeitos com a infraestrutura do curso, docentes e metodologias de ensino. As metodologias mais citadas foram palestras com profissionais do mercado; projetos interdisciplinares no curso; e metodologias inovadoras de ensino.

Os discentes apontaram conhecer os projetos de ensino, pesquisa e extensão, principalmente os projetos de pesquisa. Resultado oposto ao $1^{\circ}$ ciclo, que pode ser explicado pelo interesse dos discentes na pós-graduação e pela maturidade dos mesmos no curso.

As principais fontes de informações do curso foram o site do curso, emails informativos e o SIGAA. Todos os discentes apontaram conhecer o LABIE e LIS. Os GPs com mais participação discente são o LABIE e o GPSiCS. Os GPs que mais interessam aos discentes são LABIE e o LIS. Isso se justifica porque esses GPs possuem linhas de atuação e pesquisa mais direcionadas à área de ES, enquanto outros GPs dedicam-se a pesquisas mais específicas da EC.

Currículo do $2^{\circ}$ Ciclo. Todos os alunos conhecem a matriz curricular do $2^{\circ}$ ciclo. No entanto, a maioria deles está insatisfeita com as disciplinas do curso. O conhecimento da matriz curricular é uma das características dos BI por permitir ao discente optar por um $2^{\circ}$ ciclo. No geral, os discentes estão satisfeitos com os horários dos componentes, organização do estágio supervisionado e TCC e são unânimes na aprovação da quantidade de componentes. As áreas que os alunos mais apontaram como de interesse foram o Desenvolvimento Web e o Desenvolvimento para Dispositivos Móveis.

Mercado de Trabalho. Algo preocupante apontado pelos discentes foi que o $2^{\circ}$ ciclo não prepara para o mercado de trabalho. No entanto, a maioria deles já está trabalhando ou estagiando mesmo não concluindo o $2^{\circ}$ ciclo. A área de maior atuação e interesse dos discentes é a de desenvolvedor. Ainda foram citadas as áreas de designer e gerente de projeto. Neste sentido, torna-se importante trabalhar metodologias para os capacitar cada vez mais para as áreas de maior atuação absorvida pelo mercado alvo do curso.

Tópicos Emergentes. Dentre os tópicos emergentes sugeridos pelos discentes estão Bancos de Dados NoSQL, Firebase, que facilitam o uso no desenvolvimento mobile e Web. Foram citadas também componentes de tecnologias que estão em ascensão, como "Inteligência Artificial", "Ciência de Dados" e "Computação Estatística".

\subsection{Estratégias}

Nesta seção abordam-se algumas orientações curriculares e estratégias que estão sendo discutidas e implementadas para "minimizar" os problemas apontados pelos discentes. Estas estratégias surgiram a partir da implantação de algumas delas ao longo dos PLs, que têm se mostrado efetivas, e de ações junto a instituição para a minimizar problemas, como a falta de recursos bibliográficos.

6.2.1 Estratégias para o $1^{\circ}$ Ciclo. Referente às dificuldades dos discentes sobre a falta de atividades práticas, uma das estratégias pretendidas é alterar os planos de cursos das disciplinas para elevar o quantitativo de horas/aula práticas. Esta estratégia já foi adotada em algumas disciplinas dos PLs iniciais, com a elaboração de disciplinas de laboratório para os componentes de Algoritmos e Estruturas de Dados. No entanto, os demais componentes precisam também considerar este aspecto, principalmente, os que envolvem conteúdos comumente exigidos no mercado de trabalho.

Para minimizar a limitação de equipamentos nos laboratórios, a UFERSA-CMPF recentemente recebeu dispositivos e ambientes de informática para suprir as necessidades correntes do curso.

Buscando contribuir com a redução das dificuldades relacionadas à programação, o curso vem realizando ações de apoio ao ensino, tais como cursos temáticos de curta duração, tutoria e monitoria.

Referente ao desconhecimento dos discentes sobre os projetos de ensino, pesquisa e extensão, precisa-se realizar ações de marketing para divulgar tais projetos. Este processo já teve início com a criação e utilização de mídias sociais e site oficial do curso para divulgação a toda a comunidade acadêmica da UFERSA-CMPF. 
Para minimizar o descontentamento dos discentes com o currículo do $1^{\circ}$ ciclo, a reorganização da estrutura curricular vem sendo discutida pelo corpo docente, de forma a permitir mais eixos de formação adequados ao mercado profissional de ES. Além disso, fortalecer a oferta de componentes em áreas em ascensão no mercado, tais como desenvolvimento Web e Mobile, também se faz necessário.

6.2.2 Estratégias para o $2^{\circ}$ Ciclo. Para minimizar os problemas com à metodologia de ensino, pode-se alterar o PPC do $2^{\circ}$ ciclo para delinear estratégias de ensino-aprendizagem que favoreçam, por exemplo, o uso de metodologias ativas e inovadoras de ensino.

Da mesma forma do $1^{\circ}$ ciclo, ações precisam ser elaboradas para promover os GPs de modo a envolver, também, os discentes do $2^{\circ}$ ciclo. Estudos precisam ser feitos para identificar os motivos para a insatisfação dos discentes com as disciplinas do curso. Propõese também, a ênfase na abordagem e estudo de conteúdos que os discentes demonstraram um maior interesse e que estão mais presentes no mercado de trabalho, atualmente. Outras possibilidades também podem ser levantadas, como o desenvolvimento de produtos de software para serem lançados no mercado, novas parcerias com instituições públicas e privadas, envolvidas com produção de tecnologia, para promover atividades profissionais práticas.

\subsection{Ameaças à Validade - Limitações}

Neste estudo, alguns aspectos se destacaram, o limitando às seguintes ameaças, conforme classificação de Wohlin et al. (2012).

Validade Externa. Os participantes deste estudo não representam todos os discentes do $1^{\circ}$ e $2^{\circ}$ ciclo. Por isso, a generalização dos resultados é limitada. Destaca-se que a análise qualitativa realizada permitiu compreender aspectos da população, que dificilmente poderiam ser aprofundadas através de análises quantitativas.

Validade Interna. Para agrupar e analisar as respostas obtidas dos discentes, elaborou-se um questionário para o $1^{\circ} \mathrm{e} 2^{\circ}$ ciclo, pois o perfil de discentes difere em cada ciclo. Os discentes também podem não ter compreendido ou não ter respondido com sinceridade ou atenção às perguntas do questionário. Destaca-se que a identificação do aluno foi opcional para permitir o anonimato das respostas. As respostas ao Survey para o $1^{\circ}$ ciclo incluiu tanto inclinação para escolha de ES ou de EC, uma vez que o $1^{\circ}$ ciclo atende a diferentes perfis. No entanto, o questionário incluiu opções que permitiam ao discente informar caso não se encaixe no perfil de ES, por exemplo, indicando que não participou de disciplinas do eixo específico de ES. Outra ameaça à validade interna é a maturidade dos discentes para apontar algumas dificuldades, tais como o alinhamento dos cursos com o mercado de trabalho. Para mitigar essa ameaça, as perguntas incluíam opções que permitiam ao discente se abster, como a opção "3 = Neutro" na escala de Likert.

Validade de Constructo. Para garantir a consistência das questões apresentadas no questionário e a coerência em relação às QPs deste estudo (ver Seção 4), o questionário foi planejado e atualizado com base em estudos na área (ver Seção 3). Além das questões específicas sobre dificuldades foram adicionadas questões relacionadas a infraestrutura, formação básica e conhecimento prévio em linguagem de programação para entender motivações intrínsecas para o curso e a necessidade de modernização da infraestrutura. Ainda assim, os questionamentos podem não ter sido claros o suficiente para garantir a completude e a coerência das respostas fornecidas.
Validade de Conclusão. Para atenuar a imprecisão dos dados ou erros estatísticos foram adotados apenas valores em porcentagens para representar padrões ou dados comuns. Em relação aos procedimentos de análise adotados, na Seção 4.3 são descritas as técnicas utilizadas na análise das respostas. Algumas perguntas receberam uma porcentagem pequena de respostas válidas, como aquelas referentes às disciplinas do eixo específico. No entanto, a remoção das respostas inválidas auxiliou a manter os resultados focados nos discentes de ES e a quantidade de respostas obtidas permitiram desconsiderar algumas respostas sem comprometer o entendimento das percepções dos discentes do $1^{\circ}$ ciclo. Embora o quantitativo de discentes que responderam ao questionário do $2^{\circ}$ ciclo possa ser considerado pequeno, esse total representa a quase totalidade dos discentes do $2^{\circ}$ ciclo (70\%), o que contribui para uma visão abrangente da percepção deles sobre o curso. Uma outra ameaça é o surgimento do GP CILab (Computational Intelligence Laboratory), após a coleta de dados deste Survey. Por isso o referido GP não foi considerado neste estudo e não foi citado nas Seções 5.1.4 e 5.2.3.

\section{CONSIDERAÇÕES FINAIS}

Neste trabalho, discutiram-se os desafios e perspectivas relatados por discentes em um curso de ES, em dois ciclos. Assim, empregouse um Survey. Cada ciclo foi analisado individualmente, de acordo com o contexto acadêmico dos cursos. Foram investigadas as dificuldades nas disciplinas, as percepções dos discentes em relação ao currículo do curso e acerca do mercado de trabalho.

Os resultados obtidos indicam que as dificuldades mais relevantes no $1^{\circ}$ ciclo estão relacionadas com a pouca prática em conteúdos ministrados, à desmotivação com o curso devido à dificuldade em programar e pela quantidade de conteúdos teóricos ministrados por docentes. Sobre as percepções discentes quanto ao $2^{\circ}$ ciclo é possível destacar a satisfação quanto à matriz curricular e às perspectivas do mercado de trabalho.

Já no $2^{\circ}$ ciclo foram identificadas dificuldades com a falta de recursos bibliográficos, seguidos, em menor grau, pela indisponibilidade de ferramentas gratuitas e conteúdos muito teóricos nas disciplinas. Sobre as percepções, destaca-se o feedback positivo sobre a infraestrutura da UFERSA-CMPF, seguido pela proposta da matriz curricular. Dentre as opções ao concluir o curso, os discentes apontam o mercado de trabalho como o aspecto mais relevante.

Embora o estudo tenha sido aplicado a apenas um curso de ES em 2 ciclos, os resultados são inerentes a esta modalidade de curso, relativamente recente no Brasil, discutindo aspectos relacionados ao ensino-aprendizagem e também a temas emergentes da área. Estes resultados podem ser úteis para o delineamento de disciplinas de ES e também para direcionar o planejamento de cursos nesta modalidade. $\mathrm{O}$ trabalho é relacionado a outros estudos no contexto e pode servir de base para estudos similares em outras instituições que possuem graduação em ES ou em computação em geral.

Como trabalho futuro, pretende-se discutir os currículos do $1^{\circ} \mathrm{e}$ $2^{\circ}$ ciclo para proporcionar um ensino direcionado às necessidades desta graduação em ES, atendendo às expectativas e principais necessidades dos discentes e docentes. 


\section{REFERÊNCIAS}

[1] Claudia Bauzer Medeiros. Computação: o terceiro pilar. Revista USP, 1(89):134$147,2011$.

[2] Christiane Gresse Von Wangenheim and Djoni Antonio Silva. Qual conhecimento de engenharia de software é importante para um profissional de software? Proceedings of the Fórum de Educação em Engenharia de Software, 2:1-8, 2009.

[3] Portal e-MEC. Cadastro nacional de cursos e instituições de educação superior 2020. Disponível em http://emec.mec.gov.br/ Acessado em 9 de setembro de 2020

[4] Thaís Ferreira, Davi Viana, Juliana Costa Fernandes, and Rodrigo dos Santos. Identifying emerging topics and difficulties in software engineering education in Brazil. In Proceedings of the XXXII Brazilian Symposium on Software Engineering, SBES '18, page 230-239, 2018.

[5] Rafael Prikladnicki, Adriano Bessa Albuquerque, Christiane G von Wangenheim, and Reinaldo Cabral. Ensino de engenharia de software: desafios, estratégias de ensino e lições aprendidas. FEES-Fórum de Educação em Engenharia de Software, pages 1-8, 2009.

[6] Gatis Vitols, Irina Arhipova, and Liga Paura. Engineering study program compliance evaluation to guidelines for software engineering curriculum. Engineering for rural development. Latvia University of Life Sciences and Technologies, Jelgava, 18:1910-1914, 2019

[7] José Adson O. G. da Cunha, Gabriel A. Marques, Wellington L. Lemos, Uélio D. Câmara, and Francisco J. S. Vasconcellos. Software engineering education in Brazil: A mapping study. In Proceedings of the XXXII Brazilian Symposium on Software Engineering, SBES '18, page 348-356, New York, NY, USA, 2018. Association for Computing Machinery.

[8] Carlos S Portela, Alexandre ML Vasconcelos, and Sandro RB Oliveira. Análise da relevância dos tópicos e da efetividade das abordagens para o ensino de engenharia de software. In Fórum de Educação em Engenharia de Software (FEES). In VI Congresso Brasileiro de Software: Teoria e Prática (CBSoft), 2015.

[9] João Carlos Epifânio, Érica Miranda, Gabriela Trindade, Márcia Lucena, and Lyrene Silva. A qualitative study of teaching requirements engineering in universities. In Proceedings of the XXXIII Brazilian Symposium on Software Engineering, pages 161-165, 2019.

[10] Felipe Torres Leite, Jarbele C. S. Coutinho, and Reudismam Rolim de Sousa. An experience report about challenges of software engineering as a second cycle course. In Proceedings of the 34th Brazilian Symposium on Software Engineering, SBES '20, page 824-833, New York, NY, USA, 2020. Association for Computing Machinery.

[11] Brasil. Instituto nacional de estudos e pesquisas educacionais anísio teixeira (Inep). censo da educação superior 2018: sinopse estatística, 2019.

[12] Universidade Federal Rural do Semi-Árido. Projeto pedagógico do curso de engenharia de software, 2018. Disponível em https://engsoftwarepaudosferros. ufersa.edu.br/projeto-pedagogico-do-curso-ppc/ Acessado em 9 de setembro de 2020.

[13] SESU/MEC. Referenciais orientadores para os bacharelados interdisciplinares e similares, 2010.

[14] Brasil. Resolução ${ }^{\circ} 5$, de 16 de novembro de 2016, institui as diretrizes curriculares nacionais para os cursos de graduação na área da computação. Diário Oficial da União. Brasília, DF, n. 220, 17 novembro 2016. Seção I, p.22.

[15] Avelino F. Zorzo, Daltro Nunes, Ecivaldo S. Matos, Igor Steinmacher, Jair C. Leite, Renata Araujo, Ronaldo C. M. Correia, and Simone Martins. Referenciais de Formação para os Cursos de Graduação em Computação. Sociedade Brasileira de Computação (SBC), 2017.
[16] Pierre Bourque, Richard E. Fairley, and IEEE Computer Society. Guide to the Software Engineering Body of Knowledge (SWEBOK(R)): Version 3.0. IEEE Computer Society Press, Washington, DC, USA, 3rd edition, 2014.

[17] Rossana M de Castro Andrade, Ismayle de Sousa Santos, Italo Linhares de Araújo, Bruno Sabóia Aragão, and Fernanda Siewerdt. Retrospective for the last 10 years of teaching software engineering in ufc's computer department. In Proceedings of the 31st Brazilian Symposium on Software Engineering, pages 358-367, 2017.

[18] Cristiane Soares Ramos, Ricardo Ajax Dias Kosloski, Elaine Venson, Rejane M da Costa Figueiredo, and Victor Hugo A Deon. Tbl as an active learning-teaching methodology for software engineering courses. In Proceedings of the XXXII Brazilian Symposium on Software Engineering, pages 289-297, 2018.

[19] Jonnathan Lopes, Gabriela Medeiros, Dienefer Fialho, and Andréa Bordin. Resoluçao de problemas no curso de engenharia de software: Uma experiência envolvendo extensao e ensino. In Anais da I Escola Regional de Engenharia de Software, pages 97-104. SBC, 2017.

[20] Alessandra Dutra, Azriel Majdenbaum, Cássio Trindade, Daniele Callegari, and Marcelo Yamaguti. Percepção da contribuição da ages para o aprendizado em engenharia de software. In Anais da I Escola Regional de Engenharia de Software, pages $105-112$. SBC, 2017.

[21] Claes Wohlin, Per Runeson, Martin Höst, Magnus C Ohlsson, Björn Regnell, and Anders Wesslén. Experimentation in software engineering. Springer Science \& Business Media, 2012

[22] Duncan D Nulty. The adequacy of response rates to online and paper surveys: what can be done? Assessment \& evaluation in higher education, 33(3):301-314, 2008 .

[23] Sara Gonçalves Carneiro, Graciele Cristina Silva, Luiz Almeida da Silva, Vaston Gonçalves da Costa, and André Vasconcelos da Silva. Mulheres nas ciências de exatas, engenharia e computação: uma revisão integrativa. HUMANIDADES E TECNOLOGIA (FINOM), 1(20):159-175, 2020.

[24] Barbara Duarte, Ana Moura, and Mirella Moro. Mulheres na computação: Análises por sub-áreas. In Anais do XIII Women in Information Technology, pages 174-178. SBC, 2019.

[25] João Victor Queiroz, Larissa Milena Rodrigues, and Jarbele.C Coutinho. Um relato dos fatores motivacionais na aprendizagem de programação na perspectiva de alunos iniciantes em programação da universidade federal rural do semi-Àrido campus pau dos ferros-rn. In Proceedings of the III Encontro do Oeste Potiguar, ECOP '18, pages 90-96. ECOP, 2018.

[26] Gabriel Luídy Moreira, Wallace Holanda1, Jarbele Cássia da S. Coutinho, and Ferdinandy S. Chagas. Desafios na aprendizagem de programação introdutória em cursos de ti da ufersa, campus pau dos ferros: um estudo exploratório. In Proceedings of the III Encontro do Oeste Potiguar, ECOP '18, pages 90-96. ECOP, 2018.

[27] Reudismam Rolim de Sousa, Felipe Torres Leite, Ádller de Oliveira Guimarães, and Assunaueny Rodrigues de Oliveira. Pré-algoritmos-ações de apoio à melhoria do ensino de graduação/pre-algorithms-actions to support the improvement of undergraduate education. Brazilian fournal of Development, 6(3):12625-12635, 2020.

[28] Laís de Paiva Freire, João Victor Queiroz, Jarbele Cássia da Silva Coutinho, and Verônica Maria Lima Silva. Encontros de tutoria de programação introdutória através de metodologias ativas: um estudo piloto. In Proceedings of the I Encontro do Oeste Potiguar - Versão Pocket, IECOPPOCKET '20, pages 1-8. ECOP, 2020.

[29] Laura Isabel D. de Santana and Verônica Maria L. Silva. Projeto mulheres na computação - ufersa: um relato das ações realizadas e seus impactos na comunidade pau dos ferros. In Proceedings of the I Encontro do Oeste Potiguar - Versão Pocket, IECOPPOCKET '20, pages 1-6. ECOP, 2020. 